\title{
Contact Angle Measurements at the Interface of Co-Cr Alloy Sintered by DMLS and Coated with Hydroxyapatite
}

\author{
Diana-Irinel BĂILĂ, Cătălin ZAHARIA, Oana-Cătălina MOCIOIU
}

\begin{abstract}
The purpose of this paper consists in the evaluation of the contact angle at the interface of Co-Cr sintered samples by DMLS process. The sintered samples supported a post treatment and were coated by HA using sol-gel method and were immersed in simulated biological fluid SBFx1 for 7 days. The Co-Cr (ST2724G) sintered disks by Direct Metal Laser Sintering (DMLS) process using a Phenix Systems machine, were coated by hydroxyapatite sol-gel method for improving the bioactivity of dental implants. KSV CAM 101 apparatus is used for static contact angle measurements performed on dried films. After wetting angle determination, we can notice that the sintered samples of $\mathrm{Co}-\mathrm{Cr}$ alloy, which supported a post treatment, after DMLS process show better roughness surfaces and the layers of HA are uniformly deposited. The contact angle values are very important to characterize the surfaces and the roughness of the solid materials used for implantology. In this paper, the contact angles at the interface between $\mathrm{Co}-\mathrm{Cr}$ sintered disks coating with $\mathrm{HA}$ and distilled water reveal a hydrophilic character. Scanning electronic microscopy SEM and EDS techniques were employed for morphological investigation of the sintered samples manufactured by DMLS process. They were also used for semi-quantitative and qualitative chemical and metallographic analyses.
\end{abstract}

Keywords: Co-Cr alloy; contact angle measurement; DMLS process; hydroxyapatite; sol-gel method

\section{INTRODUCTION}

Biomaterials are biocompatible synthetic or natural compounds used for the replacement or augmentation of biological tissue. The dental implant operation represents a very great and complex series of mechanical and chemical environmental conditions.

Systematization of custom dental implant applications has led to the creation of a database that contains examples of the use of the technique DMLS - Direct Metal Laser Sintering, from image acquisition (CT), to obtaining the 3D virtual models, to produce real models.

A direct contact with the bone must contain hydroxyapatite as the bioactive phase with osteoconductive role to permit a better osseointegration.

The medical implants require a hydroxyapatite coating as bioactive phase, with an osteoconductive role, that in the direct contact with the bone permits a better osseointegration [1-9].

The external surface will be over $20 \%$ HA and the content gradually decreases.

A decrease of more than 5\% HA from one layer to another is not allowed, due to the risk of interlayer cracking increases.

The hydroxyapatite presents a low mechanical resistance. Due to this cause, the concentration of hydroxyapatite in the implant material is limited, especially if the implant supports high mechanical loads.

The biocompatible and the bioactive properties of hydroxyapatite can be recovered in functional systems such as metal substrates coated with hydroxyapatite, hydroxyapatite strengthened (reinforced) polymeric fibers or metal - in particular titanium or Co-Cr alloys, or sintered materials in Co-Cr alloy powder and hydroxyapatite.

The bioactive phase has an osteoconductive importance, because it allows the formation of new generation of calcium phosphates and permits a better integration of the dental implants of $\mathrm{Co}-\mathrm{Cr}$ alloy in the bone tissue.

Distilled water was used to determine the hydrophilic character of the Co-Cr alloy used for dental applications.
Co-Cr alloys and Ti alloys are frequently used for the implants manufacturing.

Both materials are biocompatible and can be used for manufacturing medical implants because they are not toxic for the human body [1-9].

Direct Metal Laser Sintering process consists in sinterisation by laser automatically at points in space, in relation to $3 \mathrm{D}$ model, realizing the binding powder and determining a solid structure.

The technique DMLS is successfully used for manufacturing dental restorations, like dental crowns, bridges and chapels.

The Co-Cr alloys powder has good engineering properties, good corrosion resistance and allows a good cleaning (like the glass).

The Co-Cr powder used in DMLS process presents a spherical form of the grains and the grain size is approximatly 20 microns [12-19].

The spherical form of grains permits a better sinterisation and a better powder flow.

The coating with HA sol-gel permits an improvement of bioactivity of dental implants in the bone tissue and permits mineral kernel in bone.

After immersion in SBF, the emergence of new nucleation sites of calcium phosphates can be noticed and the formation of new hydroxyapatite mineral.

The aim of our work consists in the evaluation of the contact angle at the interface of Co-Cr alloy samples and hydroxyapatite in order to establish the comportment in the simulated biological fluid [20-24].

\section{MATERIALS AND METHODS}

The samples material used in this paper is $\mathrm{Co}-\mathrm{Cr}$ powders (ST2724G) manufactured by Direct Metal Laser Sintering (DMLS) process.

The powder ST2724G shows the following chemical composition: $54,31 \% \mathrm{Co} ; 23,08 \% \mathrm{Cr} ; 11,12 \% \mathrm{Mo} ; 7,85 \%$ $\mathrm{W} ; 3,35 \% \mathrm{Si}$ and $\mathrm{Mn} ; \mathrm{Fe}<0,1$.

The mechanical properties of the $\mathrm{Co}-\mathrm{Cr}$ alloys are as follows: 
- Elastic limit $0,2 \%\left(R_{\mathrm{p} 0,2}\right)=815 \mathrm{MPa}$;

- Elongation at break $=10 \%$;

- Vickers hardness $=375$ HV 5;

- Elastic module $=229 \mathrm{GPa}$;

- Volume mass $=8,336 \mathrm{gcm}^{-3}$

- Corrosion resistance $<4 \mu \mathrm{g} / \mathrm{cm}^{2}$;

- Thermal expansion coefficient $=14.5^{*} 10^{-6} \mathrm{~K}^{-1}$.

The sintered disks by DMLS process have a thickness of $1 \mathrm{~mm}$ and a diameter of $10 \mathrm{~mm}$.

The sintered disks were designed in Solid Works and saved like "stl" file.

The DMLS process was performed using a Phenix Systems machine, type PXS \& PXM Dental.

The Phenix Systems machine has the following main characteristics: the fiber laser $P=50 \mathrm{~W}, \lambda=1070 \mathrm{~nm}$, manufactured volume is $100 \times 100 \times 80 \mathrm{~mm}$, machine dimensions are $L=1,20 \mathrm{~m} ; l=0,77 \mathrm{~m} ; H=1,95 \mathrm{~m}$.

The machine uses Phenix Dental soft. The sintered process is realized at the temperature of $1300^{\circ} \mathrm{C}$ and in the presence of nitrogen gas for 30 minutes.

The samples were slowly air cooled.

Two samples were introduced in the furnace to realize a post treatment of $800{ }^{\circ} \mathrm{C}$ during 30 minutes and slowly cooling in the air to obtain a better mechanical resistance.

Four DMLS sintered samples of $\mathrm{Co}-\mathrm{Cr}$ were mechanically polished and coated with HA sol-gel method.

The samples were cleaned with distilled water and alcohol before coating deposition.

The four samples sintered by DMLS technique were coated with hydroxyapatite by sol-gel method. The sol-gel process was realized after the technique of Fathi and Hafini [10].

$\mathrm{P}_{2} \mathrm{O}_{5}$, Merck was dissolved in absolute ethanol to obtain a $0,5 \mathrm{~mol} / 1$ solution.

$\mathrm{Ca}\left(\mathrm{NO}_{3}\right)_{2} \cdot 4 \mathrm{H}_{2} \mathrm{O}$, Merck was dissolved in absolute ethanol to realize a $1,67 \mathrm{~mol} / \mathrm{l}$ solution.

The homogenization of the solutions was realized on a magnetic stirrer, in a molar ratio of $\mathrm{Ca} / \mathrm{P}=1,67$; for 48 hours, to make the sol-gel transition.

The sintered samples were immersed in the precursor solutions using a constant speed of immersion and lifting of $50 \mathrm{~mm} / \mathrm{min}$.

The samples were introduced in solution for 60 seconds.

Then, the coated sintered disks were dried for 10 minutes and supported thermal treatment in an electrical furnace in air atmosphere.

The thermal treatment was realized in two steps: for 16 hours at $80{ }^{\circ} \mathrm{C}$ and 1 hour at $600{ }^{\circ} \mathrm{C}$. The sintered disks were slowly cooled to $20^{\circ} \mathrm{C}[11]$.

The presence of calcium phosphates on the surface of the dental implants increases the bioactivity behaviour by formation of new hydroxyapatite and favours a better osseointegration of the implants within the bone.

The four samples were immersed in simulated biological fluid $\mathrm{SBF}$ at $\mathrm{pH}=7,4$, for 7 days, adjusted with tris (hydroxy-methyl) aminomethane (Tris) and hydrochloric acid $(\mathrm{HCl})$, in sterile conditions, using the containers of $45 \mathrm{~mL}$ for incubation medium at the temperature of $37^{\circ} \mathrm{C}$.

The simulated biological fluid solution was changed every $48 \mathrm{~h}$. After immersion in SBF the samples were rinsed with distilled water and were dried at $40{ }^{\circ} \mathrm{C}$ for 24 h.

The SBF1x solution has the following chemical composition: $142,19 \mathrm{mM}\left(\mathrm{Na}^{+}\right) ; 2,49 \mathrm{mM}\left(\mathrm{Ca}^{2+}\right) ; 1,5 \mathrm{mM}$ $\left(\mathrm{Mg}^{2+}\right) ; 4,2 \mathrm{mM}\left(\mathrm{HCO}_{3}^{-}\right) ; 141,54 \mathrm{mM}\left(\mathrm{Cl}^{-}\right) ; 0,9 \mathrm{mM}$ $\left(\mathrm{HPO}_{4}{ }^{2-}\right) ; 0,5 \mathrm{mM}\left(\mathrm{SO}_{4}{ }^{2-}\right) ; 4,85 \mathrm{mM}\left(\mathrm{K}^{+}\right)$.

The contact angle was determined at the interface of Co-Cr alloy samples sintered by DMLS technology and coated with hydroxyapatite by sol-gel, using a contact angle apparatus, made in Finland.

KSV - CAM 101 apparatus is used to determine the surface and interfacial tension, the static and dynamic contact angles and the surface free energy of solids.

In this paper, KSV CAM 101 apparatus was used for static contact angle measurements performed on dried films. Ultrapure water droplets were used with a drop volume of $20 \mu \mathrm{l}$. The measurement of each contact angle was made within $10 \mathrm{~s}$ after each drop to ensure that the droplet did not soak into the compact. The contact angles reported were the mean of 5 determinations. Smaller contact angles correspond to increased wettability. Four specimens of $\mathrm{Co}-\mathrm{Cr}$ sintered samples manufactured by DMLS technology and coated with HA by sol-gel were used.

Meniscus formed immediately after the surface was viewed through a stereoscopic microscope, the optical beam was deflected horizontally by a mirror precision.

The resulting image was processed on a computer software to measure the wetting angles.

The morphology and semi-quantitative analysis of sintered disks were investigated by scanning electron microscope QUANTA INSPECT F equipped with electron gun with field emission -FEG (field emission gun) with a resolution of $1.2 \mathrm{~nm}$ and X-ray spectrometer for energy dispersion (EDS) with a resolution of $133 \mathrm{eV}$ at $\mathrm{MnK}$.

The chemical composition of the sintered samples was realized with images of secondary electrons and backscattered electron images, the bright contrast micro areas contained heavy elements (no. Atomic large) and the dark contrast of light elements was employed. The areas of interest were analysed qualitatively by micro compositional X-ray spectrometry.

\section{RESULTS}

\subsection{Determination of Contact Angles for the Sintered Samples of Co-Cr Coated with HA}

In Fig. 1 there are presented the Co- $\mathrm{Cr}$ sintered disks by DMLS technology and coated with hydroxyapatite, using sol-gel method.

The probes were immersed in simulated biological fluid for 7 days. Then the probes were prepared for determining the contact angle curvature.

The contact angle curvature for a 3D drop is given by Young-Laplace equation and is non-linear [1-3].

$$
K_{\mathrm{m}}=\frac{1}{2} \cdot \frac{\left(1+f_{x}^{2}\right) \cdot f_{y y}-2 \cdot f_{x} \cdot f_{y} \cdot f_{x y}+\left(1+f_{y}^{2}\right) \cdot f_{x x}}{\left(1+f_{x}^{2}+f_{y}^{2}\right)^{\frac{3}{2}}}
$$

This equation permits to determine the $3 \mathrm{D}$ shape of drop and represents the energy minimization method. The 
wetting angles are obtained in laboratory in proper conditions using clean solid surfaces and purified liquid, like distilled water.

The contact angles are very sensitive to contamination noticed in the variation of the values obtained, and some degrees of difference existed.

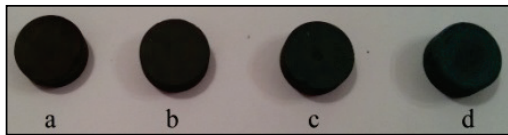

Figure 1 Sintered disks of Co-Cr by DMLS technology and coated with HA by sol-gel

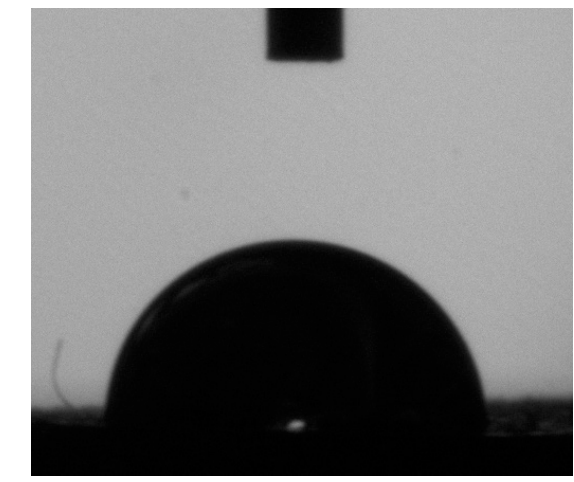

Figure 2 Contact angle curvature for the sintered sample 1

The contact angle is very sensitive to the chemical composition of alloy, the oxide layer or contaminant existing on the surface and this is remarked in the value obtained with their variations, using the system KSV CAM 101

The drop shape presented in Fig. 2 shows the angle measurement of nearly $89,8^{\circ}$ and in Fig. 3 shows the stabilisation of curvature angle in time, at $65^{\circ}$.

That shows that the first sample of $\mathrm{Co}-\mathrm{Cr}$ sintered by DMLS process without post treatment process and which was coated with one layer of HA and immersed in SBF for 7 days presents a hydrophilic surface.

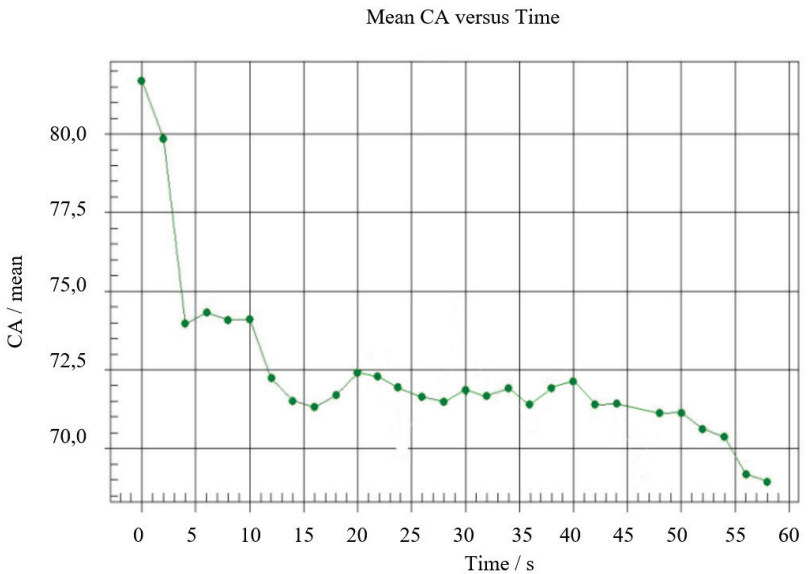

Figure 3 Variation of contact angle curvature in time for the sintered sample 1

The contact angle curvature for the sample of $\mathrm{Co}-\mathrm{Cr}$ sintered by DMLS, without post treatment and coating twice layers with HA and immersed in SBF for 7 days is shown in Fig. 4 and can remarked the hydrophilic characteristic is very pronounced.

The variation in function of the time for the wetting angle curvature for sample 2 is presented in Fig. 5. For Fig.
4 the angle is nearly $59,5^{\circ}$ and after a minute the angle is stabilized to $51,5^{\circ}$, like in Fig. 5 .

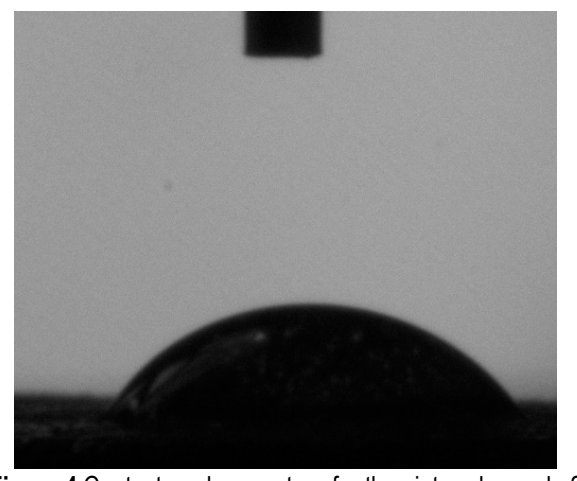

Figure 4 Contact angle curvature for the sintered sample 2

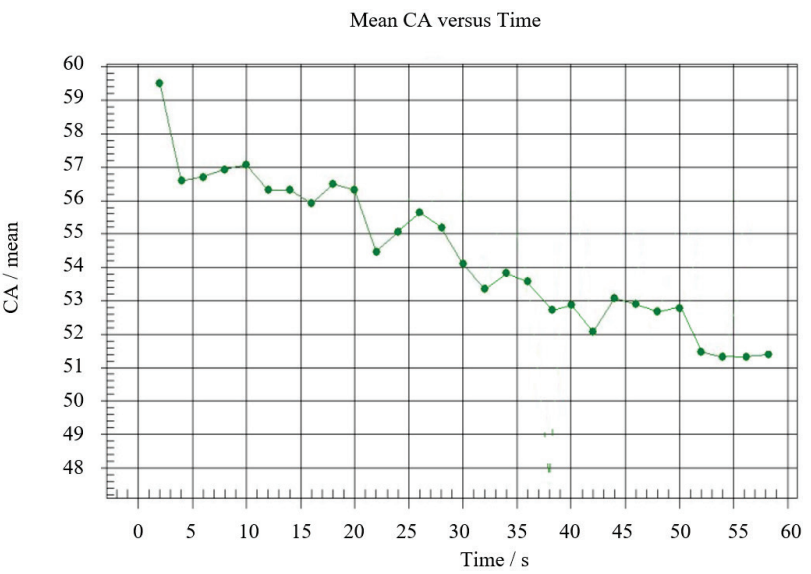

Figure 5 Variation of contact angle curvature in time for the sintered sample 2

The contact angle curvature for the sintered sample 3 is presented in Fig. 6.

The sample 3 of Co-Cr alloy was sintered by DMLS process, supported a post treatment in the furnace at 800 ${ }^{\circ} \mathrm{C}$ during 30 minutes, then one layer was coated with HA, and immersed in SBF for 7 days.

The wetting angle for the sample 3 is nearly $65^{\circ}$. The sample 3 shows a pronounced hydrophilic property.

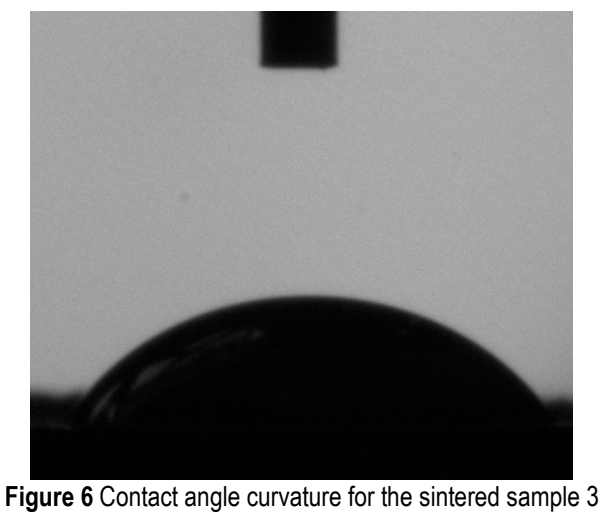

In Fig. 7 one can determine the variation of wetting angle curvature in time and after a minute the curvature is stabilized to $52,8^{\circ}$.

The contact angle curvature for the sintered sample 4 is presented in Fig. 8.

The sample 4 of Co-Cr was sintered DMLS, supported a post-sintering treatment and was coated with two layers 
of hydroxyapatite and then was introduced in SBF for 7 days.

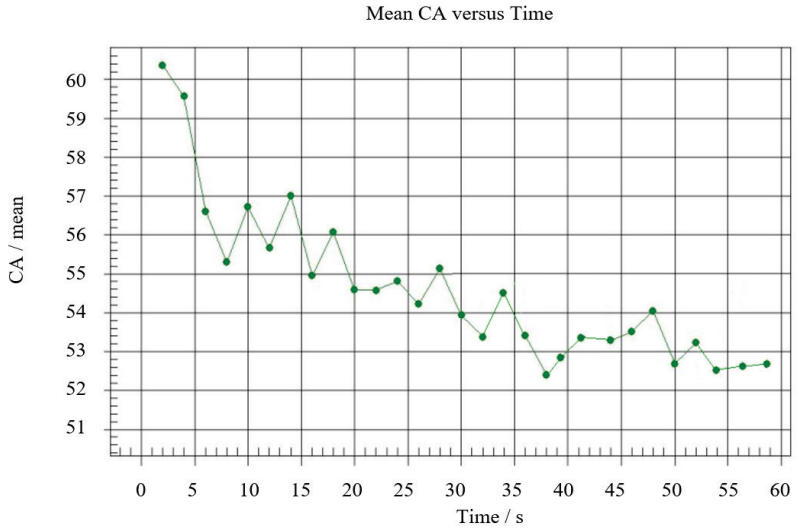

Figure 7 Variation of contact angle curvature in time for the sintered sample 3

The contact angle for the sample 3 is nearly $75,2^{\circ}$, like in Fig. 8 and after a minute the angle is stabilized to $45^{\circ}$, like in Fig. 9.

The sintered sample 4 has a very pronounced hydrophilic property.

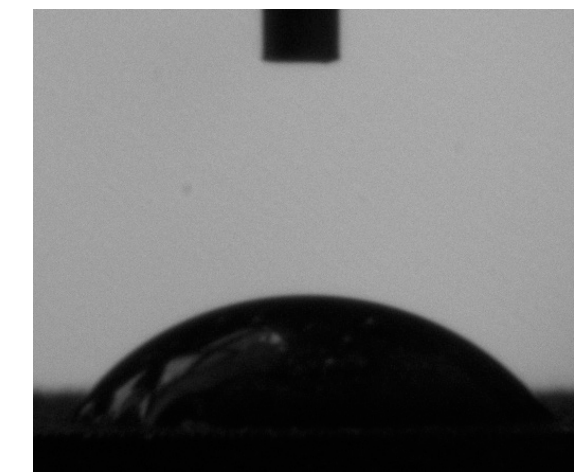

Figure 8 Contact angle curvature for the sintered sample 4

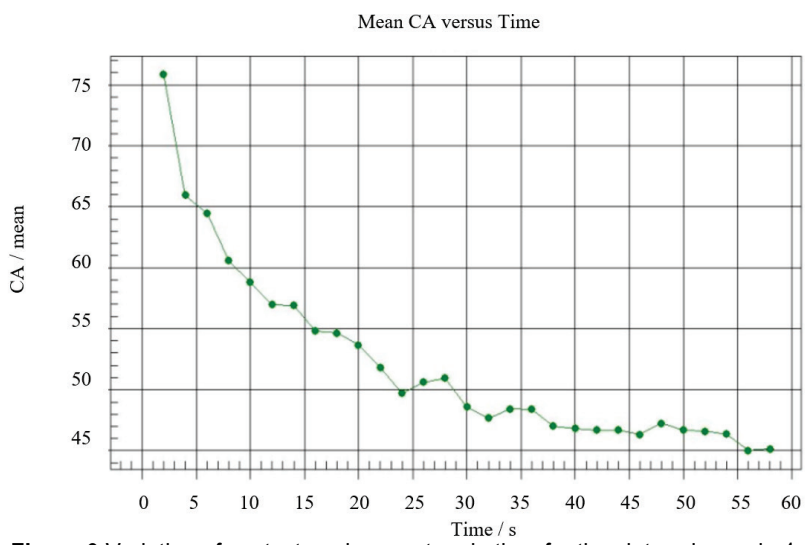

Figure 9 Variation of contact angle curvature in time for the sintered sample 4

\subsection{SEM and Mapping Analysis of Co-Cr Alloy Sintered Samples by DMLS and Coated With HA}

The morphological investigations and chemical elemental analysis of the four DMLS sintered samples were realized by SEM and mapping analysis. A very fine uniform layer of HA with equiaxed grains between 40 - 100 $\mathrm{nm}$ is presented in the sintered sample 1.

The mapping of the sintered sample 1 is shown in Fig. 11 and the majority presence of $\mathrm{Co}, \mathrm{Cr}, \mathrm{W}, \mathrm{Ca}, \mathrm{P}$ and other chemical elements can be remarked.

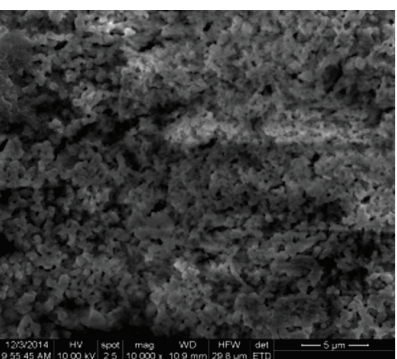

$X 10000$

Figure 10 SEM analysis of the sintered sample 1

The SEM analysis of sintered sample 2, like in Fig. 12, reveals a compact film of HA with irregular and elongated grain form, between $30-40 \mathrm{~nm}$. In Fig. 12 one can notice few $\mathrm{Co}-\mathrm{Cr}$ spherical grains after the cleaning process in DMLS.

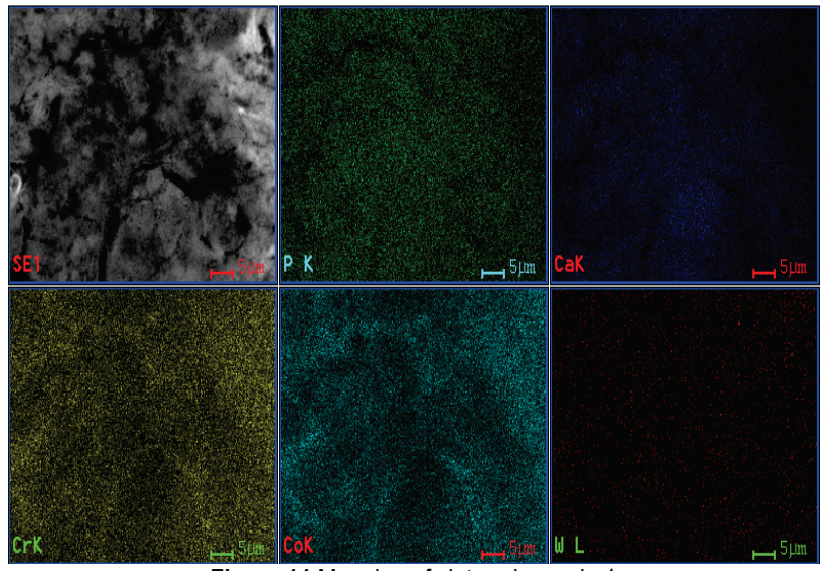

Figure 11 Mapping of sintered sample 1

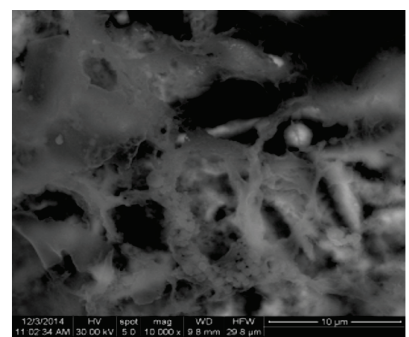

$X 10000$

Figure 12 SEM analysis of the sintered sample 2

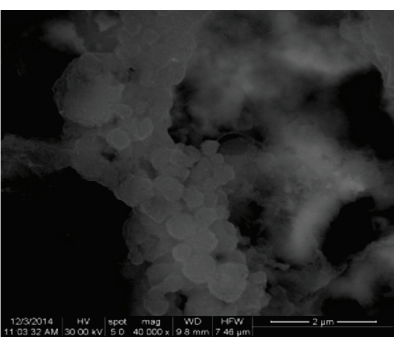

$X 40000$

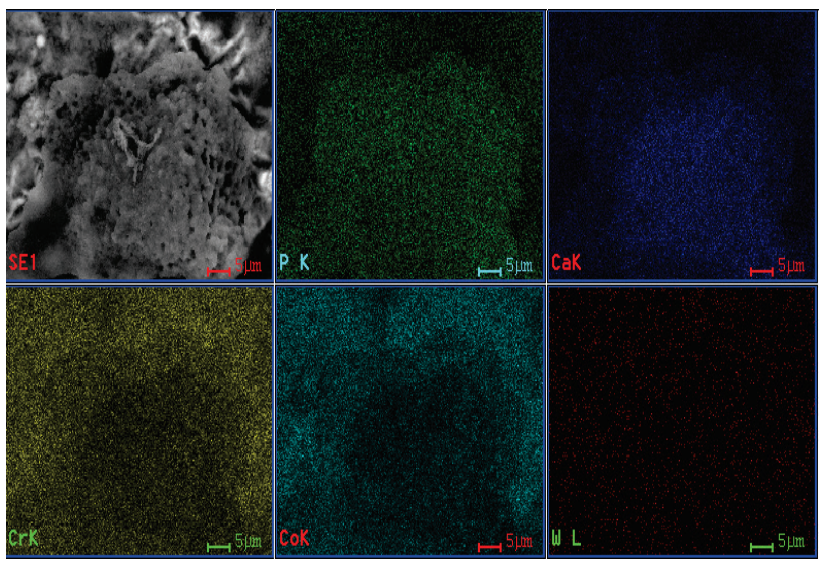

Figure 13 Mapping of sintered sample 2

The mapping of sintered sample 2 presents the uniform distribution of $\mathrm{Ca}, \mathrm{P}, \mathrm{Co}, \mathrm{Cr}, \mathrm{W}$ and other elements (Fig. 13). 


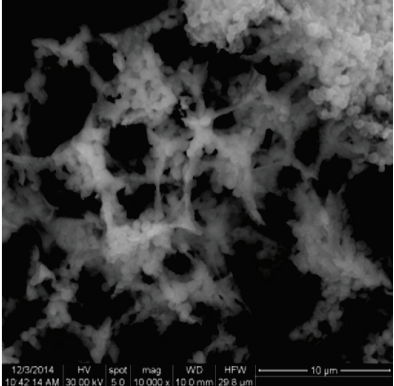

$X 10000$

Figure 14 SEM analysis of the sintered sample 3

The SEM analysis of sintered sample 3 is shown in Fig. 14 and the thin layer of nanostructured hydroxyapatite can be remarked.

The mapping of the sintered sample 3 is presented in Fig. 15 and the presence of $\mathrm{Co}, \mathrm{Cr}, \mathrm{W}, \mathrm{Ca}, \mathrm{P}$ and other chemical elements as well as the uniform distribution can be determined.

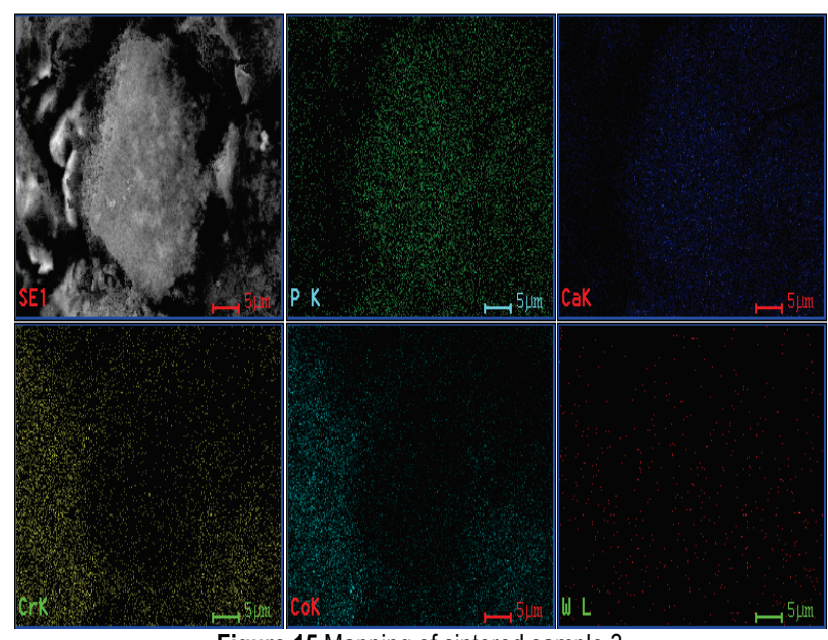

Figure 15 Mapping of sintered sample 3

The SEM analysis of sintered sample 4 is shown in Fig. 16 and one can remark the fine deposition of HA film, with grain forms between $40-70 \mathrm{~nm}$.

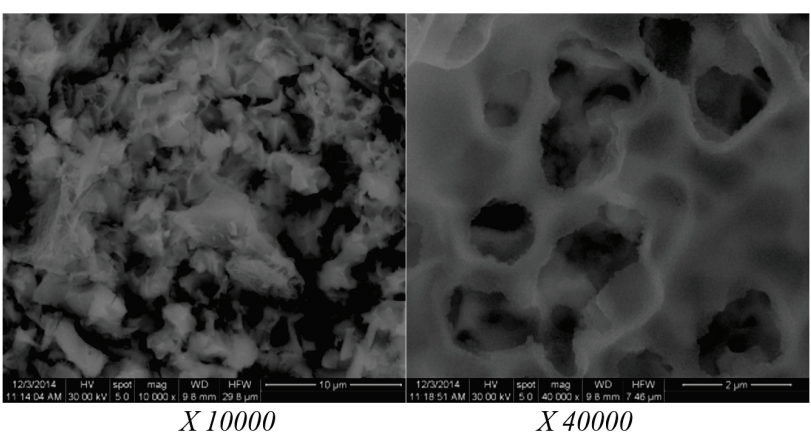

Figure 16 SEM analysis of the sintered sample 4

The mapping of the sintered sample 4 is realized in Fig. 17 and the aglomeration with hydroxyapatite is very pronounced.

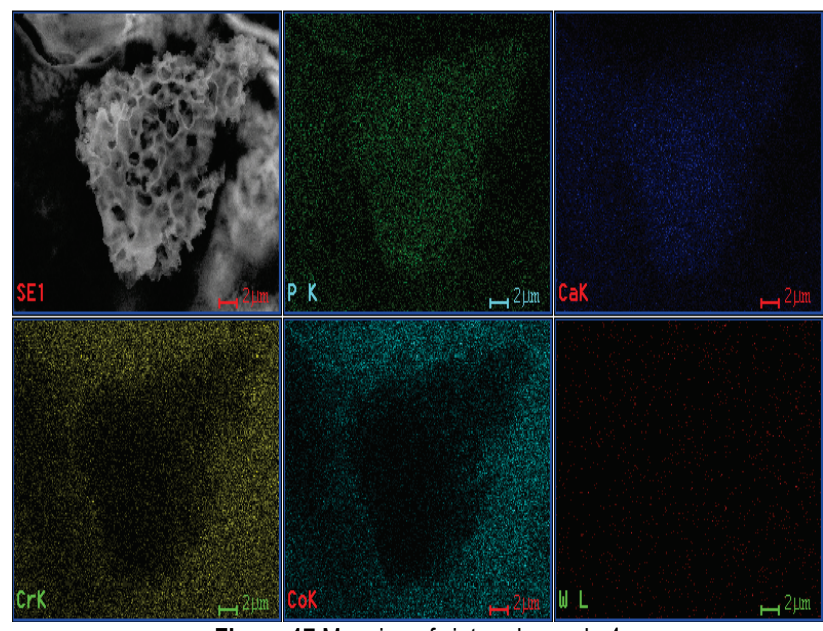

Figure 17 Mapping of sintered sample 4

\section{CONCLUSIONS}

The static wetting angle is measured for quality control, in research domain and for development of product. The static contact angle determinations are used in domains ranging from printing to oil recovery and implants coatings.

The static contact angles were determinated in this paper, using four sintered samples of $\mathrm{Co}-\mathrm{Cr}$ alloy, by DMLS technology. Two samples 3 and 4 supported the post treatment in the furnace to $800^{\circ} \mathrm{C}$, during 30 minutes and two samples 1 and 2 were used without post treatment. Two samples were coated with one HA layer by sol-gel method, and the samples were coated with two layers of HA. Then the four samples were immersed in SBF, during 7 days.

All four sintered samples show a hydrophilic behaviour due to the HA layers. The two samples coated with two layers of HA present an accentuated hydrophilic behaviour. The layers of HA deposited on the sintered samples are uniform, and that is remarked after the mapping and SEM analysis.

The sintered samples of $\mathrm{Co}-\mathrm{Cr}$ that supported a post treatment, after DMLS process, due to wetting angle value present a better roughness surfaces and the layers of HA are uniformly deposed.

The contact angle values of the four sintered samples determine the chemical homogenous and topographic smooth.

For coating implants, the contact angle values play a vital role to determine a precise characterization of the surfaces of the solid materials, because the roughness surfaces are very important for the medical implants.

In our case, the wettability was determined using distilled water to calculate the homogenous chemical composition, surface uniformity. The wettability behavior is very important for adherence of the medical implants in the bone tissue. The more hydrophilic material allows a better adherence in the bone tissue, that means the sample 4 permits a better osseointegration, after implantation to the bone tissue.

Wettability of implant surfaces is important to be evaluated for $3 \mathrm{D}$ printing and for characterizing the cellbiomaterial interactions. 


\section{Acknowledgement}

This work has been funded by the University Politehnica of Bucharest, through the "Excellence Research Grants" Program, UPB - GEX. Identifier: UPBEXCELENTTĂ-2016 Research project title "Experimental researches concerning new biocompatible materials manufacturing by DMLS process used for personalized dental implants and restorations/Cercetări experimentale privind utilizarea de noi materiale biocompatibile destinate implanturilor și restaurărilor dentare personalizate fabricate prin sinterizare DMLS", Contract number 29/26.09.2016.

\section{REFERENCES}

[1] Ihrig, J. L. \& Lai, D. Y. F. (1957). Contact angle measurement. Journal of Chemical Education, 34(4), 196. https://doi.org/10.1021/ed034p196

[2] Gesser, H. D. \& Krause, P. (2000). A demonstration of surface tension and contact angle. Journal of Chemical Education, 77(1), 58. https://doi.org/10.1021/ed077p58

[3] https://en.wikipedia.org/wiki/Contact_angle.

[4] Sorkin, A., Tan, J. L., \& Wong, C. H. (2017). Multi-material modeling for selective laser melting. Procedia Engineering, 216, 51-57. https://doi.org/10.1016/j.proeng.2018.02.088

[5] Jinoop, A. N., Subbu, S. K., \& Kumar, A. R. (2018). Mechanical and microstructural characterization on direct metal laser sintered Inconel 718. International Journal of Additive and Subtractive Materials Manufacturing, 2(1), 112. http://doi.org/10.1504/IJASMM.2018.093250

[6] Sedlak, J., Ptackova, M., Nejedly, J., Madaj, M., Dvoracek, J., Zouhar, J., Charvat, O., Piska, M., \& Rozkosny, L. (2013). Material analysis of titanium alloy produced by Direct Metal Laser Sintering. International Journal of Metalcasting, 7(2), 43-50. https://doi.org/10.1007/BF03355552

[7] Silver, F. H. \& David, L. (1999). Biomaterials science and biocompatibility. Springer Verlag. https://doi.org/10.1007/9781-4612-0557-9

[8] Joon, B. P. \& Bronzi, J. D. (1999). Biomaterials. Principles and Applications. CRC Press.

[9] Buddy, D. R., Hoffman, S., Schoen, F., \& Lemons, J. (1996). Biomaterials Science, An introduction to materials in medicine. Academic Press.

[10] Fathi, M. H. \& Hafini, A. (2009). Sol-gel derived nanostructure hydroxyapatite powder and coating: aging time optimization. Advances in Applied Ceramics, 108(6), 363-368. https://doi.org/10.1179/174367609X414080

[11] Ozgur, E. \& Cuneyt Tas, A. (2000). Preparation of porous $\mathrm{Ca} 10(\mathrm{PO} 4) 6(\mathrm{OH}) 2$ and $\beta-\mathrm{Ca} 3(\mathrm{PO} 4) 2$. Journal of American Ceramic Society, 83(7), 1581-1584. http://doi.org/10.1111/j.1151-2916.2000.tb01434.x

[12] Tang, Y. C., Katsuma, S., Fujimoto, S., \& Hiromoto, S. (2006). Electrochemical study of type 304 and 316L stainless steels in simulated body fluids and cell cultures. Acta Biomaterialia, 2, 709-715. https://doi.org/10.1016/j.actbio.2006.06.003

[13] Gibson I. \& Shi D. (1997). Material properties and fabrication parameters in selective laser sintering process. Rapid Prototyping Journal, 3(4), 129-136. https://doi.org/10.1108/13552549710191836

[14] Hryniewicz, T., Rokosz, K., \& Filippi, M. (2009). Biomaterial Studies on AISI 316L Stainless Steel after Magnetoelectropolishing, Materials Journal, 2, 129-145. https://doi.org/10.3390/ma2010129

[15] Hunt, J. A., Callaghan, J. T., Sutcliffe, C. J., Morgan, R. H., Halford, B., \& Black, R. A. (2005). The design and production of Co-Cr alloy implants with controlled surface topography by CAD-CAM method and their effects on osseointegration. Biomaterials Journal, 26, 5890-5897. https://doi.org/10.1016/j.biomaterials.2005.03.004

[16] Boutrand, J. P. (2012). Biocompatibility and performance of medical devices. Woodhead Publishing Series in Biomaterials. https://doi.org/10.1533/9780857096456

[17] Maszybrocka, J., Stwora, A., Gapinski, B., Skrabalak, G., \& Karolus, M. (2017). Morphology and surface topography of Ti6Al4V lattice structure fabricated by selective laser sintering. Bulletin of the Polish Academy of Sciences: Technical Sciences, 65(1), 85-92. https://doi.org/10.1515/bpasts-2017-0011

[18] Da Silva Bartolo, P. J., de Lemos, A. C., Pereira, \& A. M. (2013). High Value Manufacturing: Advanced Research in Virtual and Rapid Prototyping. CRC Press.

[19] http://www.phenix-systems.com/en/materials.

[20] Mangano, F., Chambrone, L., van Noort, R., Miller, C., Hatton, P., \& Mangano, C. (2014). Direct Metal Laser Sintering titanium dental implants: a review of the current literature. International Journal of Biomaterials, 2014, 1-11. https://doi.org/10.1155/2014/461534

[21] Jyotirmoy, N., Hrushikesh, S., \& Seshadev, S. (2017). Modeling of microstructure evolution in direct metal laser sintering: A phase field approach. IOP Conference Series: Materials Science and Engineering, 1-8. https://doi.org/10.1088/1757-899X/178/1/012028

[22] Walczak, R. (2018). Inkjet 3D printing - towards new micromachining tool for MEMS fabrication. Bulletin of the Polish Academy of Sciences: Technical Sciences, 66(2), 179186.

[23] Băilă, D. I., Mocioiu, O. C., Trușcă R., Surdu, A., Zaharia, C., \& Bunea, R. (2016). Biodegradation and mechanical behaviour of sintered compacts of Co-Cr alloy powder doped with $\mathrm{ZrO} 2$ used in dentistry. Vjesnik Gazette, 23(4), 10471057. https://doi.org/10.17559/TV-20150315185808

[24] Tanski, T., Matysiak, W., Kosmalska, D., Lubos, A. (2018). Influence of calcination temperature on optical and structural properties of $\mathrm{TiO} 2$ thin films prepared by means of sol-gel and spin coating. Bulletin of the Polish Academy of Sciences: Technical Sciences, 66(2), 151-156. http://doi:10.24425/119069

\section{Contact information}

Diana-Irinel BĂILĂ, PhD, Eng

University POLITEHNICA of Bucharest,

Spl. Independentei, No. 313, district 6, 060042, Bucharest, Romania

E-mail: baila_d@yahoo.com

Cătălin ZAHARIA, Prof. PhD, Eng.

University POLITEHNICA of Bucharest,

Spl. Independentei, No. 313, district 6, 060042, Bucharest, Romania

E-mail: zaharia.catalin@gmail.com

Oana-Cătălina MOCIOIU, Senior Researcher PhD, Eng

"llie Murgulescu" Institute of Physical Chemistry of Romanian Academy,

Spl. Independentei, No.202, district 6, 060021, Bucharest, Romania

E-mail: oana.mocioiu@yahoo.com 